\title{
Photovoltaic grid-connected with transformer less renewable source system with multilevel NPC inverter
}

Anchal Yadav* and Pratibha Tiwari

\author{
Department of Electrical Engineering, \\ VIAET, \\ Sam Higginbottom University of Agriculture, \\ Technology and Sciences, \\ Allahabad, 211007, UP, India \\ Email: Anchalyadav992@gmail.com \\ Email: Pratibha.tiwari@shuats.edu.in \\ *Corresponding author
}

\begin{abstract}
In research used permanent magnet synchronous generator. AC grid linked by wind energy with a load. The loads in a grid might be harmful to nature. Hence, the injection of unbalance current into renewable grid should be avoided since these Negative sequence currents and harmonic currents will cause an unwanted improvement of the current line. Dealing with problems is to use effective controllers with multilevel inverters. A multilevel inverter handed down to improve THD. In this case, a nine-level and an eleven-level inverter are used for the set the values of voltage increment and THD decrease with $12.87 \%$ to $4.38 \%$. Powers is a limitation of stabilisation of DC and the power of reactive is close to unity. Low capacitors filter to eradicate the harmonics presence in the system. For the performance evaluation of the approaching for a modelling of the $\mathrm{AC}$ grid, nonlinear load, multilevel inverter and renewable energy resources (e.g., wind power generation) was developed in a MATLAB / SIMULINK environment.
\end{abstract}

Keywords: wind energy; permanent magnet synchronous motor; PMSM; total harmonic distortion; THD; multilevel inverter.

Reference to this paper should be made as follows: Yadav, A. and Tiwari, P. (2020) 'Photovoltaic grid-connected with transformer less renewable source system with multilevel NPC inverter', Int. J. Digital Signals and Smart Systems, Vol. 4, Nos. 1/2/3, pp.133-146.

Biographical notes: Anchal Yadav is doing PhD in Electrical Engineering at Sam Higgin bottom University of Agriculture Science and Technology, Prayagaraj. She has done her MTech in Electrical Engineering (Control and Instrumentation) from Sam Higgin bottom University of Agriculture Science and Technology, Prayagaraj in 2016 with silver medal. In 2014, she has done BTech in Electronics and Instrumentation Engineering from the Integral University Lucknow with 1st division with honours. She has very good knowledge of MATLAB/SIMULINK and she has published almost 15 papers, some in journals and some is conference of during research. She has done lots of workshop and seminar related the course.

Pratibha Tiwari is an Assistant Professor in Department of Electrical Engineering at Sam Higgin bottom University of Agriculture Science and Technology, Prayagaraj. She has done BTech in United College of Engineering, Prayagraj and MTech in Motilal Nehru National Institute of 
Technology, Prayagaraj. She obtained degree of $\mathrm{PhD}$ in Electrical Engineering at Sam Higgin bottom University of Agriculture Science and Technology, Prayagaraj. She has done the work as advisor more than 20 students of the MTech and 50 above student of BTech. She published 50 above research paper and she has experience of teaching 15 years. She has very good expert of control system.

This paper is a revised and expanded version of a paper entitled 'Photovoltaic grid-connected with transformer less renewable source system with multilevel NPC inverter' presented at International Conference on Sustainable Energy, Electronics and Computing-SEEMS, Greater Noida, 26-27 October 2018.

\section{Introduction}

We know about the energy demand day by day increasing according to the human needs. They are used for technology, source's they make lots of hubs so that's why energy consumes more and more. So we can refer for power conversion topologies which improve our cost, or any kind of economic effect.

The next stage of electrical equipment's improvement of the latest power conversion topologies related with semiconductors. When developed the scenario of the total power it is also affect cost. So we can choose a suitable medium for the economic. So according to the previous research, they focus on the various type of the renewable energy source. Which are shows the powers varieties, as a key requirement everything depends on the power electronics with an ultimate power which given confirm quality energy. Recently there is a very tough competition between conversions of power topologies and high voltage semiconductors. A proper way of this type converter its type of race, which all of the situations moves the power of voltage and current semiconductors. There are lots of parameters for overcome the problems for delay the signals and turn on for real components. It is given a real-time to turn point, which reduces the effect and improves the system. Multilevel converter is beneficial for the nowadays technology. So there is a multilevel converter advantages:

- quality of power

- losses of low switching

- $\mathrm{EMC}$

- cost profits.

After that some disadvantages also of multilevel inverter:

- the complexity of large number semiconductors switches

- use of capacitor bank with own creation the de voltage steps.

It is given a visible reason to show capability and low stress with simply controlling medium. Multilevel converter topologies are given the most common way. Then topologies are (Uehara et al., 2011):

- diode-clamped 
- $\quad$ flying capacitor

- $\quad$ cascaded topology.

\section{Layout of the research}

In this paper divided by mainly six sections which are as follows:

Section 2 is literature review and the previous work done by another authors which has knowledge of renewable source system with photovoltaic grid-connected design modelling is discussed. This Section 3 gives brief information about how the technological advancement has led and made strong base of power converters and renewable source system in implementation of advanced photovoltaic grid model with simulation. Section 4 presents the multilevel inverter topology with neutral point-clamped inverter. In this section focused on the design and modelling of the motors which used here. In this section the working and operation of motor is discussed as well as mathematical model along with PM machine synchronously rotating $d-q$ reference frame. Section 5 discusses photovoltaic grid-connected with diode-clamped circuit topologies of multilevel inverter:

a three-level

b five-level.

Section 6 simulation and result we are exploring waveform of ac grid connected load:

a voltage at inverter

b voltage at load

c RMS voltage at inverter

d RMS current of load at terminal ab

e RMS current of load at terminal ab

f rotor speed

$\mathrm{g}$ frequency.

Section 7 conclusions are drawn from the work done and helpful for the future scope of the research topic.

\section{Literature and review}

The request for energy in this world day by day is growing. There is more reason to why this happing, here proper hub of technologies which provide some new production, source, and so many electric power. They should be used for the so many works. Here system task they provide high efficiency with lots of responsibilities. Today, multilevel converter is so good for carry a high power and mature semiconductor which convert from $1 \mathrm{MW}$ to $30 \mathrm{MW}$. Here we can assume a bond for maximum power for three phases which bound given maximum voltage and currents limits. We can overcome the limitation by parallel and series switches, its connecting several solutions. If we use one 
component switches it is faster to another. We use mostly parallel connection is given the less complicated coefficient property of MOSFETs and IGBTs with the increment of junction temperature. Beside the generation, electric power transmission needs high power electronic systems to assure conversion and the energy quality. Numerous industry applications, such as for example textile and paper industry, steel mills, electric and hybrid electric vehicles, ship propulsion, railway traction, 'more-electric' aircraft, etc., require utilisation of variable speed electric drives.

Furthermore, higher is the power of a switch lower is the switching frequency. An initial solution to overcome these limitations was connection of several switches in series or in parallel. The series connection of two or more semiconductor devices faces problems due to the difficulty to synchronise perfectly their commutations 2015 (Ullah et al., 2007).

In fact, if one component switches off faster than the others it will blow up because it will be subject to the entire voltage drop designed for the series. Instead, parallel connection is slightly less complicated because of the positive resistance coefficient property of MOSFETs and IGBTs with the increment of junction temperature. When a component switches on faster than the others do, it will conduct a current greater than the rated one. In this way, the component increases its junction temperature and its resistance, in this way limiting the current to some extent. This effect makes possible to overcome the problems coming from a delay among gate signals or from differences among real turn on time of the components. Nevertheless, parallel connection of the switches has its limits: it requires careful I precise design of the system to achieve almost perfect symmetry of the components, a task more difficult to maintain as their number rises. Another way, we can acknowledge of arising problems from delay among gate signals. It is given a real-time to turn point, which reduces the effect and improves the system. Multilevel converter is beneficial for the nowadays technology in 2014 (Pouresmaeil et al., 2012).

We are using equation related to the wind turbine in Sections 3 and 4 with multiple variables which are very useful in this research. After this entire scenario we need to add some special values of switching states of the five-level inverter using by table in Table 1. So we can see equations (1) to (6) explain in Section 3 with lots of varying rotor speed. So how to work turbine wind we can assume easily. Then next Section 4 which is describes the permanent magnet synchronous motor (PMSM) with equations (7) to (18). Which are connected to each other simultaneously and it is improve the quality. In this section we are talking about rotor and motor with various examples.

\section{Modelling of wind turbine for power system}

We have used characteristics of the system turbine which output depends on the wind speed. It may be defined scenario between the total power and the wind of the mechanical.

$$
P_{\text {wind }}=1 / 2 \rho \pi R_{\text {turbine }}^{2} v_{\text {wind }}^{3}
$$

where the air density of $\rho$ is $\left(1,225 \mathrm{~kg} / \mathrm{m}^{3}\right)$, rotor turbine defined by $R$. Speed of wind is $v$. Exploring all the energy of system choose kinetic energy which is impossible for wind. Shown in (2) as the power coefficient $C_{p}$. 


$$
P_{m}=1 / 2 C_{P} \rho \pi R_{\text {turbine }}^{2} v_{\text {wind }}^{3}
$$

Mechanical power defined by $P_{m}$ of wind. The highest power is 0.59 . Betz limits defined the value of velocity $\lambda$ which reduce sometimes. The angle of light $\theta: C_{p}=C_{p}(\lambda, \theta)$. Define reduce speed $\lambda$ of the rotor.

$$
\lambda=\Omega R_{\text {turbine }} / v_{\text {wind }}
$$

Let the values of wind constant speed $v_{\text {wind }}$, the remove speed $\lambda$ varies proportionally to the speed rotor (Agarwal et al., 2012). In modern wind turbines, the naturalisation angles of the blade are possible through a control mechanism (Agarwal and Agarwal, 2012). Here specific curve $C_{p}-\lambda$ is the rotor $R_{\text {turbine }}$. Calculated the output torque of the turbine using:

$$
T_{m}=P_{m} / \Omega=1 / 2 C_{p} \rho \pi R_{\text {turbine }}^{2} v_{\text {wind }}^{3} / \Omega
$$

The optimal value of the speed ratio of $\lambda$ maintained the value of rotor output, a maximum value of power coefficient is $C_{p M}=C_{p}\left(\lambda^{o p t}\right)$, then the maximum power of wind will be:

$$
P_{m}^{o p t}=1 / 2 C_{p M} \rho \pi R_{\text {turbine }}^{2} v_{\text {wind }}^{3}
$$

If, we assumed the ratio of speed which is maintained the optimal value. On another side, we collect the optimum values:

$$
\lambda^{\text {opt }}=\Omega R_{\text {turbine }} / v_{\text {wind }}=\Omega^{\text {opt }}=\lambda^{\text {opt }} v_{\text {wind }} / R_{\text {turbine }}
$$

Here shown all term in Figure 1.

Figure 1 Wind turbine power characteristics (see online version for colours)

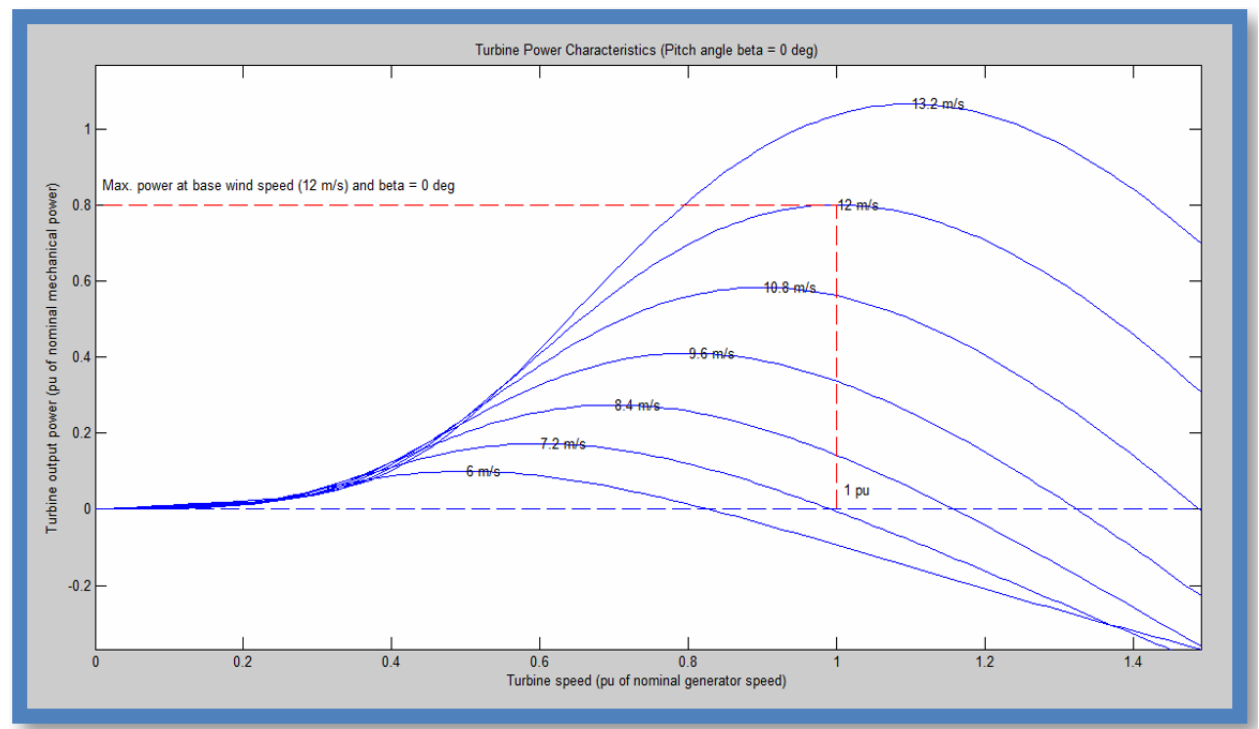


We are finding out the output mechanical torque of wind and rotor speed.

\section{Modelling and simulation of PMSM}

The references of a synchronously rotating rotor which use stator winding values which transform rotor speed with rotating reference frame that revolving sometimes. In the form of mathematical PMSM use the vector control dynamic model $\mathrm{d}-\mathrm{q}$ which contained a good model of an induction machine with an equation of damper winding.

PMSM model without damper winding collect frame of the rotor reference use the assumptions:

1 neglected saturation

2 sinusoidal EMF induced

3 neglected core losses

4 field current dynamics is not available.

Given the operating point which has rotor flux is null and exploring along zero flux in $d$ axis and also $q$ axis, coincidence assumption of indirect vector command induction motor portion is also similar. If the frame of rotor reference is assumed, it means $d$ and $q$ stator winding reference frames of the transformed and revolving speed of the rotor. The rotor reference using flux linkage of stator equations are taken into the PSMS model which derives all equation which related to the stator shown in Figure 2.

Here it is given so many equations which are very suitable for the system stability its using for constant rotor flux for $q$ axis which is given zero flux supposed to similar. This is based on the derivation of indirect vector of controlled induction motor drives. The induction machine of rotor reference with stator equation connected with linkage flux of model driven by permanent magnet synchronous motor as shown in Figure 2.

Figure 2 PM machine synchronously rotating $d-q$ reference frame (see online version for colours)

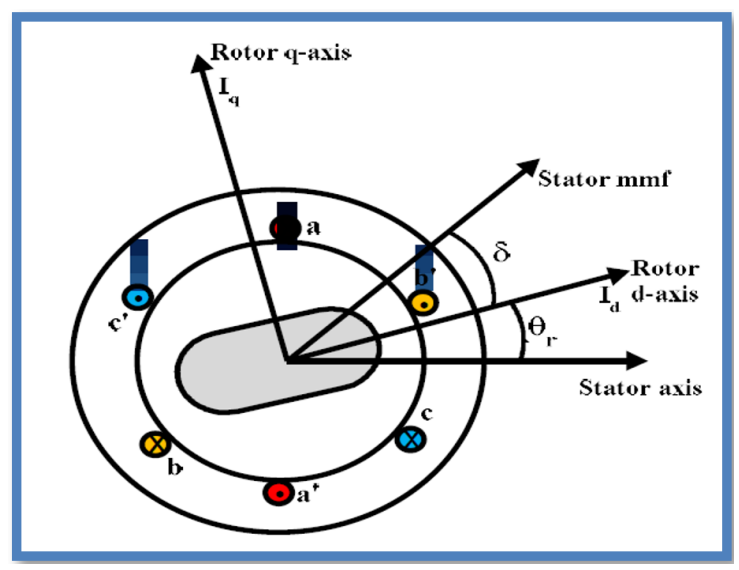

We can see a PM machine derive by the all set of an equation and general terms: 
Voltage equation derived by:

$$
\begin{gathered}
V_{d}=R_{s} i_{d}-\omega_{r} \lambda_{q} \\
V_{q}=R_{s} i_{q}-\omega_{r} \lambda_{d}
\end{gathered}
$$

Flux linkages are given by:

$$
\begin{aligned}
& \lambda_{q}=L_{q} i_{q} \\
& \lambda_{d}=L_{d} i_{d}+\lambda_{f}
\end{aligned}
$$

Substituting (9) and (10) into (7) and (8), we get:

$$
\begin{aligned}
& V_{q}=R_{s} i_{q}+\omega_{r}\left(L_{d} i_{d}+\lambda_{f}\right)+\left(L_{q} i_{q}\right) \\
& V_{d}=R_{s} i_{d}-\omega_{r} L_{q} i_{q}+\left(L_{d} i_{d}+\lambda_{f}\right)
\end{aligned}
$$

Arranging equations (11) and (12) in a matrix, we get:

$$
\begin{aligned}
& \left(V_{q}\right)=\left(R_{s}+d L_{q} w_{r} L_{d}\right)\left(i_{q}\right)+\left(W_{r} \lambda_{f}\right) \\
& \left(V_{d}\right)=\left(-w_{r} L_{q} R_{s}+d L_{q} / d t\right)\left(i_{d}\right)+\left(d \lambda_{f} / d t\right)
\end{aligned}
$$

The developed torque motor is being given by:

$$
\begin{aligned}
& T_{e}=3 / 2(P / 2)\left(\lambda_{d} i_{q}-\lambda_{q} i_{d}\right) \\
& T_{e}=3 / 4 P\left[\lambda_{f} i_{q}+\left(L_{d}-L_{q}\right) i_{q} i_{d}\right] \\
& T_{e}=T_{L}+B \omega_{m}+J
\end{aligned}
$$

Solving for all term (16), we get:

$$
\omega_{m}=\left(T_{e}-T_{L}-B \omega_{m} / J\right) d t
$$

And rotor electrical speed is:

$$
\omega_{r}=\omega_{m}(P / 2)
$$

\section{A new multilevel inverter topology photovoltaic grid-connected}

Here describing the all over works of inverter topologies in Figure 3(a). Here DC bus split in two way with heavy capacitor series and point $\mathrm{n}$ is the kind of central capacitors. The values of output voltage have three states, positive negative and neutral. Here output voltage mention in term of $V_{a n}$.

For positive output voltages are good and ON mode of switches. For negative output voltage is also $\mathrm{ON}$, and for ground level most ON mode.

Here used elements of the key that connected to the circuit which is conventional derive $D_{1}$ and $D_{2}$ level of an inverter. This voltage uses half level of dc-bus voltage. $V_{a 0}=V_{d c}$, then $S_{2}$ and $S_{1}$ are $\mathrm{ON}$. 
We can see, balance out the voltage $D_{1}$, sharing between $S_{1}$ and $S_{2}$ then $S_{1}$ block across voltage $C_{1}$ and $S_{2}$ block $C_{2}$.In all the scenario we can notice $V_{a n}$ is ac and $V_{a 0}$ is dc in output voltage. These voltages difference covering $C_{2}$, it is $V_{d c} / 2$. If we are removed output voltage a to 0 its circuit becomes de to dc converter.

Figure 3 Diode-clamped circuit topologies of multilevel inverter, (a) three-level (b) five-level (see online version for colours)

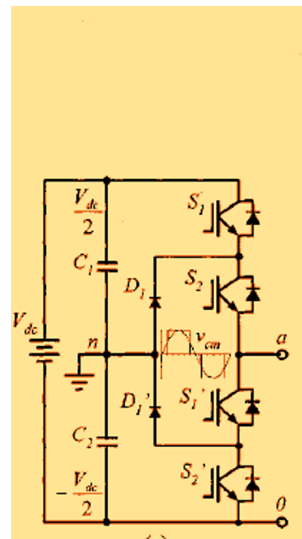

(a)

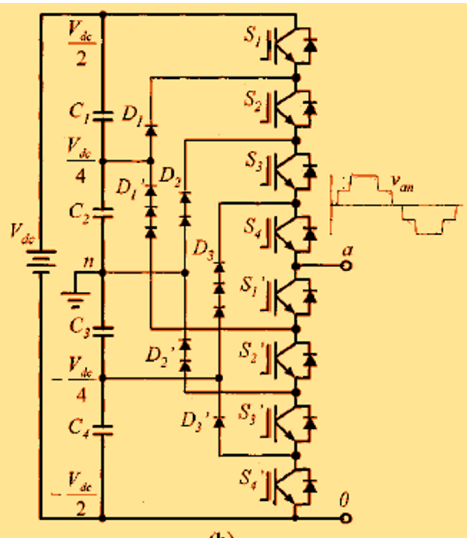

(b)

To explain how the staircase voltage is synthesised, the neutral point $n$ is considered as the output phase voltage reference point. There are five switch combinations to synthesise five level voltages across $a$ and $n$ :

1 for voltage level $V_{a n}=V_{d c} / 2$, turn on all upper switches $S_{1}-S_{4}$

2 for voltage level $V_{a n}=V_{d c} / 4$, turn on three upper switches $S_{2}-S_{4}$ and one lower switch $S_{1}^{\prime}$

3 for voltage level $V_{a n}=0$, turn on two upper switches $S_{3}$ and $S_{4}$ and two lower switches $S_{1}^{\prime}$ and $S_{2}^{\prime}$

4 for voltage level $V_{a n}=-V_{d c} / 4$, turn on one upper switch and three lower switches $S_{1}^{\prime}-S_{3}^{\prime}$

5 for voltage level $V_{a n}=-V_{d c} / 2$, turn on all lower switches $S_{1}^{\prime}-S_{4}^{\prime}$.

Four complementary switch pairs exist in each phase. The complementary switch pair is defined such that turning on one of the switches will exclude the other from being turned on. In this example, the four complementary pairs are $\left(S_{1}, S_{1}^{\prime}\right),\left(S_{2}, S_{2}^{\prime}\right),\left(S_{3}, S_{3}^{\prime}\right)$, and $\left(S_{4}, S_{4}^{\prime}\right)$.

However, increase the no. of a level of control complexity which introduces voltage imbalance issues. Figure 3(b) showing the system materials with suitable way. In $V_{d c}$ voltage use dc-bus, and across each capacitor $V_{D C} / 4$, and they have stress voltage is short-term duration capacitor by clamping-diode. 
Table 1 Switching states of the five-level inverter

\begin{tabular}{lcccccccc}
\hline \multirow{2}{*}{ Output $v_{a 0}$} & \multicolumn{10}{c}{ Switch states } \\
\cline { 2 - 9 } & $S_{1}$ & $S_{2}$ & $S_{3}$ & $S_{4}$ & $S_{1}^{\prime}$ & $S_{2}^{\prime}$ & $S_{3}^{\prime}$ & $S_{4}^{\prime}$ \\
\hline$V_{3}=V_{d c}$ & 1 & 1 & 1 & 1 & 0 & 0 & 0 & 0 \\
$V_{4}=3 V_{d c} / 4$ & 0 & 1 & 1 & 1 & 1 & 0 & 0 & 0 \\
$V_{3}=V_{d c} / 2$ & 0 & 0 & 1 & 1 & 1 & 1 & 0 & 0 \\
$V_{2}=V_{d c} / 4$ & 0 & 0 & 0 & 1 & 1 & 1 & 1 & 0 \\
$V_{1}=0$ & 0 & 0 & 0 & 0 & 1 & 1 & 1 & 1 \\
\hline
\end{tabular}

Although each active switching device is only required to block a voltage level of $V_{d c} /(m-1)$, the clamping diodes must have different voltage ratings for reverse voltage blocking. Using $D_{1}^{\prime}$ of Figure 3 as an example, when lower devices $S_{2}^{\prime} \sim S_{4}^{\prime}$ are turned on, $D_{1}^{\prime}$ needs to block three capacitor voltages, or $3 V_{d c} / 4$.

Similarly, $D_{2}$ and $D_{2}^{\prime}$ need to block $2 V_{d c} / 4$, and $D_{3}$ needs to block $3 V_{d c} / 4$. Assuming that each blocking diode voltage rating is the same as the active device voltage rating, the number of diodes required for each phase will be $(m-1)(m-2)$.

This number represents a quadratic increase in $m$. When $m$ is sufficiently high, the number of diodes required will make the system impractical to implement. If the inverter runs under PWM, the diode reverse recovery of these clamping diodes becomes the major design challenge in high-voltage high-power applications.

\section{Simulation and result}

The simulation system of an 11-level neutral point clamped (NPC) multi-level inverter with AC grid into renewable resources is validated by simulation of the circuit in MATLAB/SIMULINK. It is express by the blade of the turbine and the transferred energy to the turbine rotor which is connected to a common shaft connecting the PMSG (PMSM). The energy of mechanical is converted by the PMSG (PMSM) to AC voltages which fluctuates bond with wind speed. The three-phase ac voltage is then converted into dc using a three-phase rectifier. The NPC topology of the MLI blocks the dc component from entering the grid and provides feasible application of control technique used switches in this system. The simulation system of 11-levels NPC multi-level inverter with renewable energy resources in to $\mathrm{AC}$ grid is validated by simulation of the circuit in MATLAB/SIMULINK environment. The entire wind energy conversion system is as shown in figure. The blades of the turbine capture wind energy and transfer energy to the turbine rotor which is connected to a common shaft connecting the PMSG (PMSM). PMSG (PMSM) converts this mechanical energy to three phase ac voltage which fluctuates according to the wind speed. This three phase ac voltage is converted into dc by a three phase rectifier. Output dc voltage is fed to a boost converter which boosts the input signal voltage and feeds an amplified dc voltage to the MLI. The NPC topology of the MLI blocks the dc component from entering the grid and provides feasible application of control technique for the switches. 
- wind speed

- $\quad$ rotor speed

- pitch angle

- electromagnetic torque

- mechanical torque.

Figure 4 Schematic model of AC grid-connected renewable energy resources with NPC multi inverter (see online version for colours)

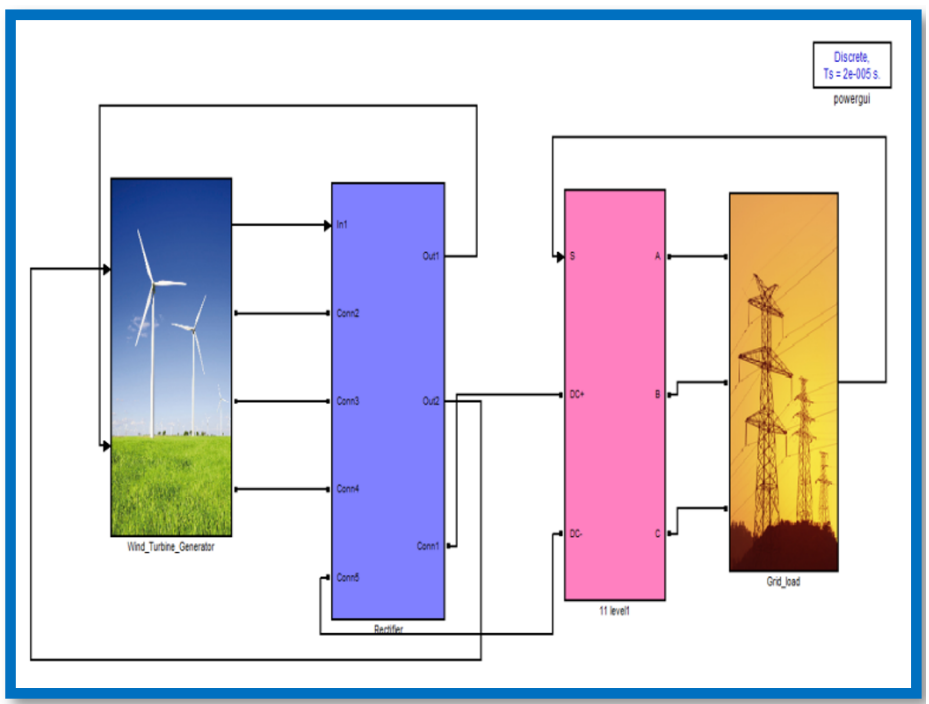

Figure 5 Simulink of rectifier (see online version for colours)

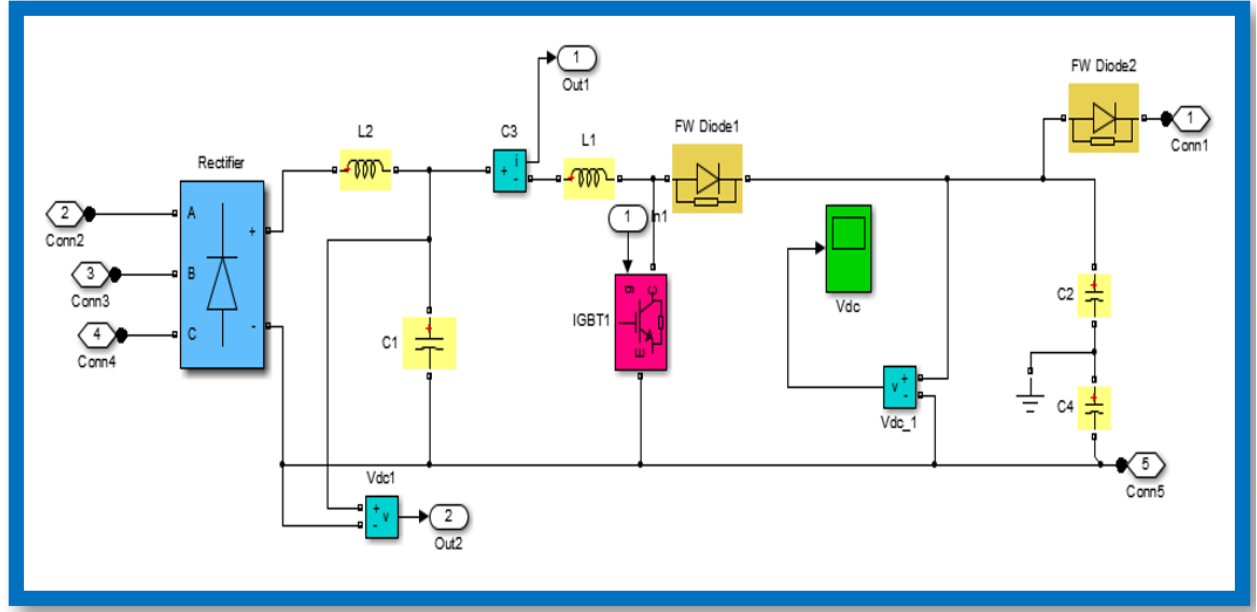


Figure 6 Waveform of wind turbine (see online version for colours)

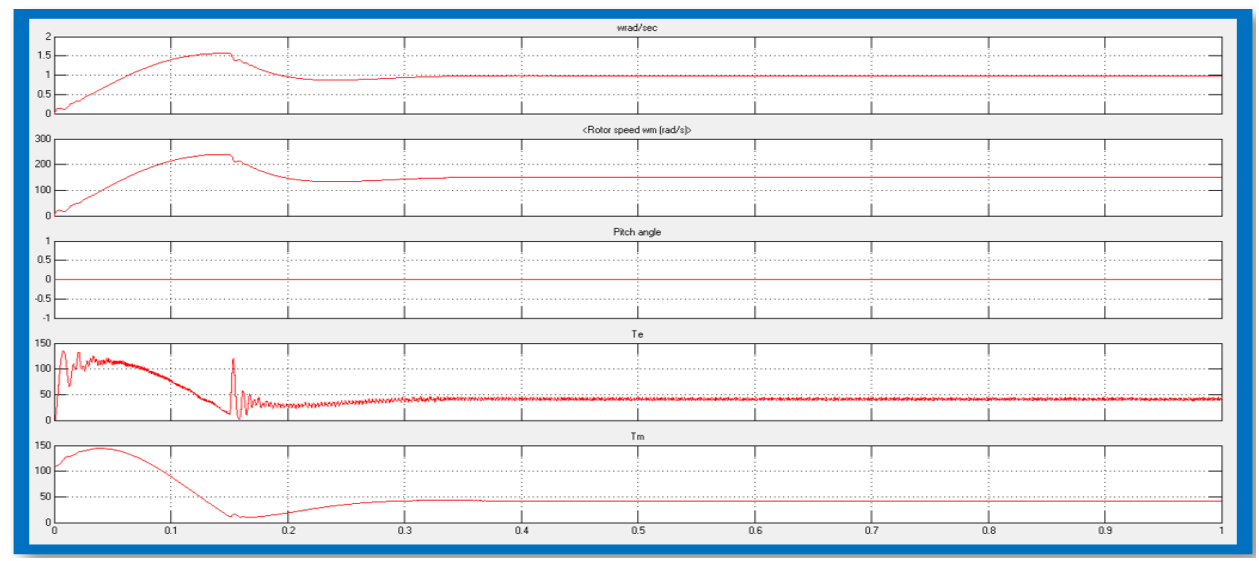

Figure 7 Waveform of generator terminal, (a) voltage at stator terminal of ab (b) current of line (c) RMS voltage at stator terminal of ab (d) RMS current of line (e) generated power (f) rotor speed (see online version for colours)

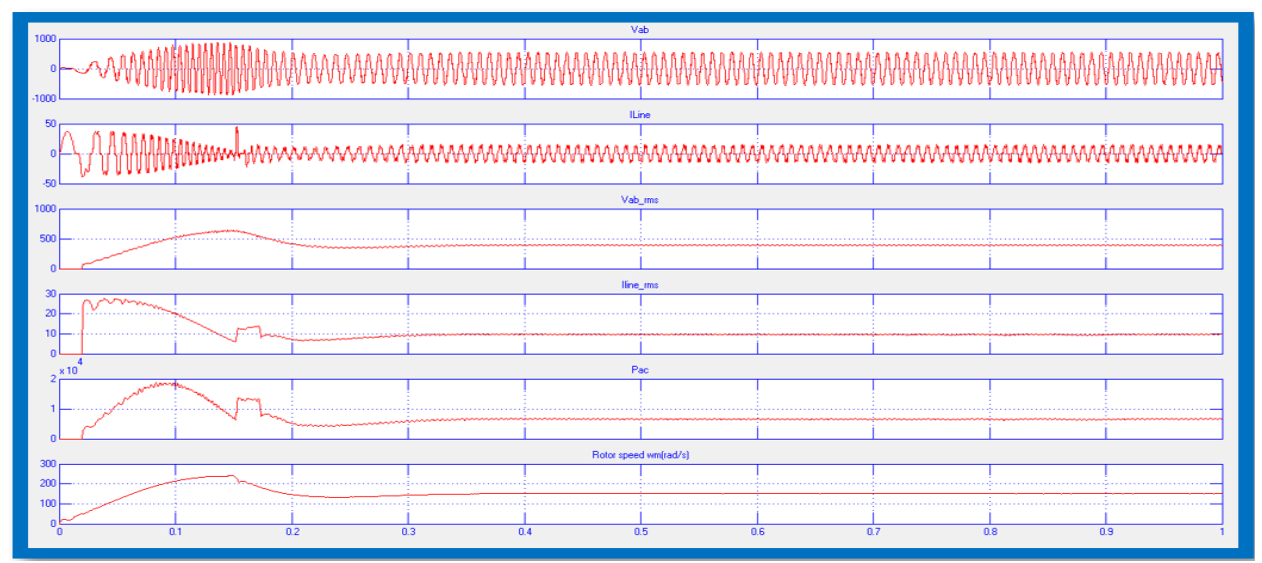

\section{Conclusions}

In this research, the presentation of 11-levels NPC inverter combine with renewable energy sources with AC grid performances. Using 11-levels NPC Converter, the whole system will declines output harmonic effectively while improving power capacity of whole equipment, and reducing the voltage stress of switch and the equivalent switching frequency. 
Figure 8 Output waveform of lower half 11-level NPC multi inverter (see online version for colours)
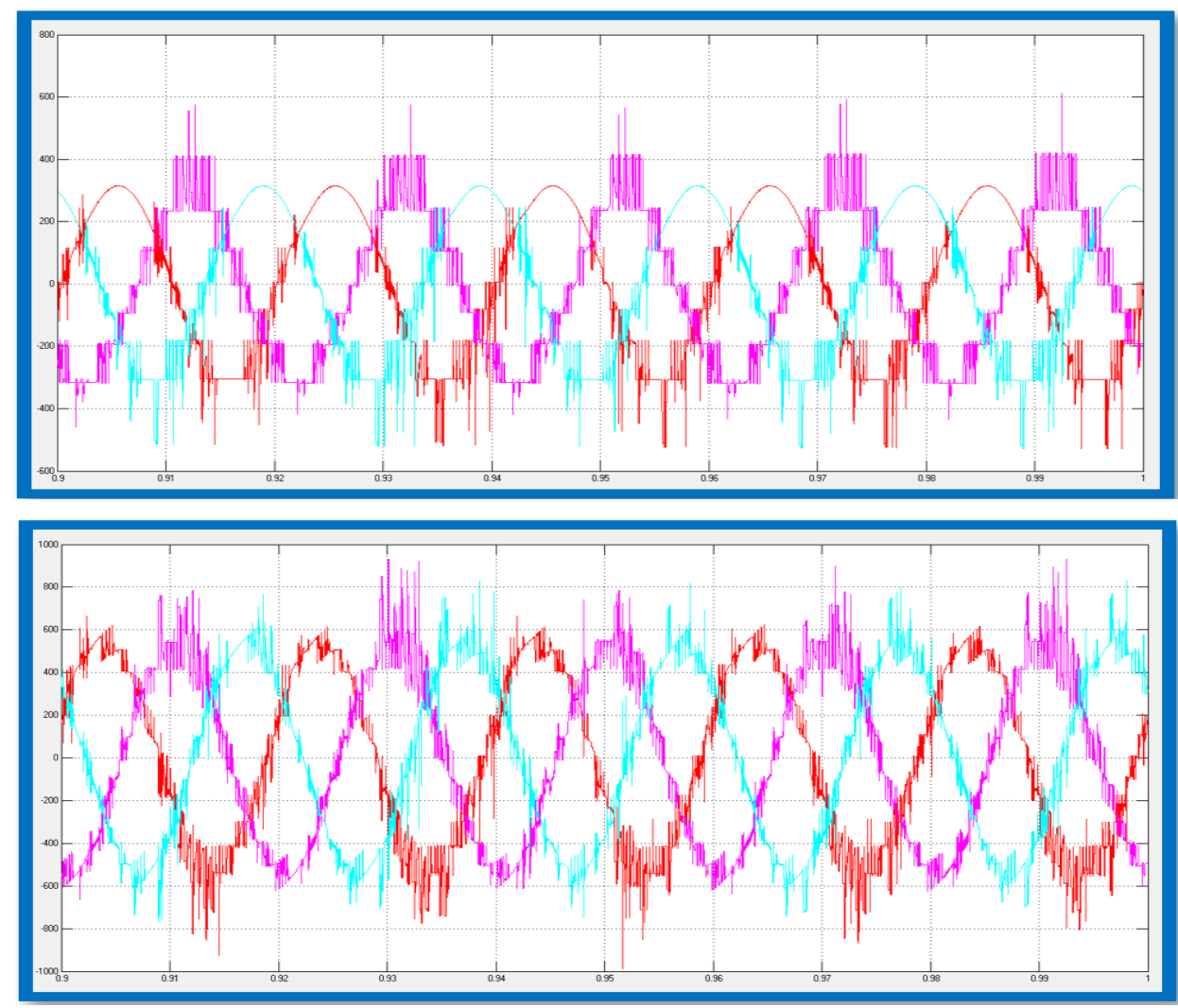

Wind speed have main role in this whole research. It is verifying current and voltage with these effects also. Here the speed of power grid is decreases with active and reactive powers, and controller of pitch angle apply the control blade angle at $\theta=0$ with controlling system. We proposed a method of control which capability manage all type of converter topologies and apply so many different varieties of combine renewable energy source into AC grids. Here also use multi-objective program with this renewable resources.

The staging of an 11-level NPC inverter to united renewable energy resource into AC grid is performing. Using the 11-level NPC converter, the output results of harmonics the whole system is effectively decreasing the voltages. With varying wind speeds, the current also vary which in turn affects the grid power, and here used wind turbine which speed decreases with all powers. The pitch angle became 0 . The model given through generator side can accomplish. And the highest power of wind tracing, closed-loop control based on the highest ratio of torque to current. The portion of the grid aligns, realising the active decoupling control and reactive power. 
Figure 9 Simulink model of AC grid connected load (see online version for colours)

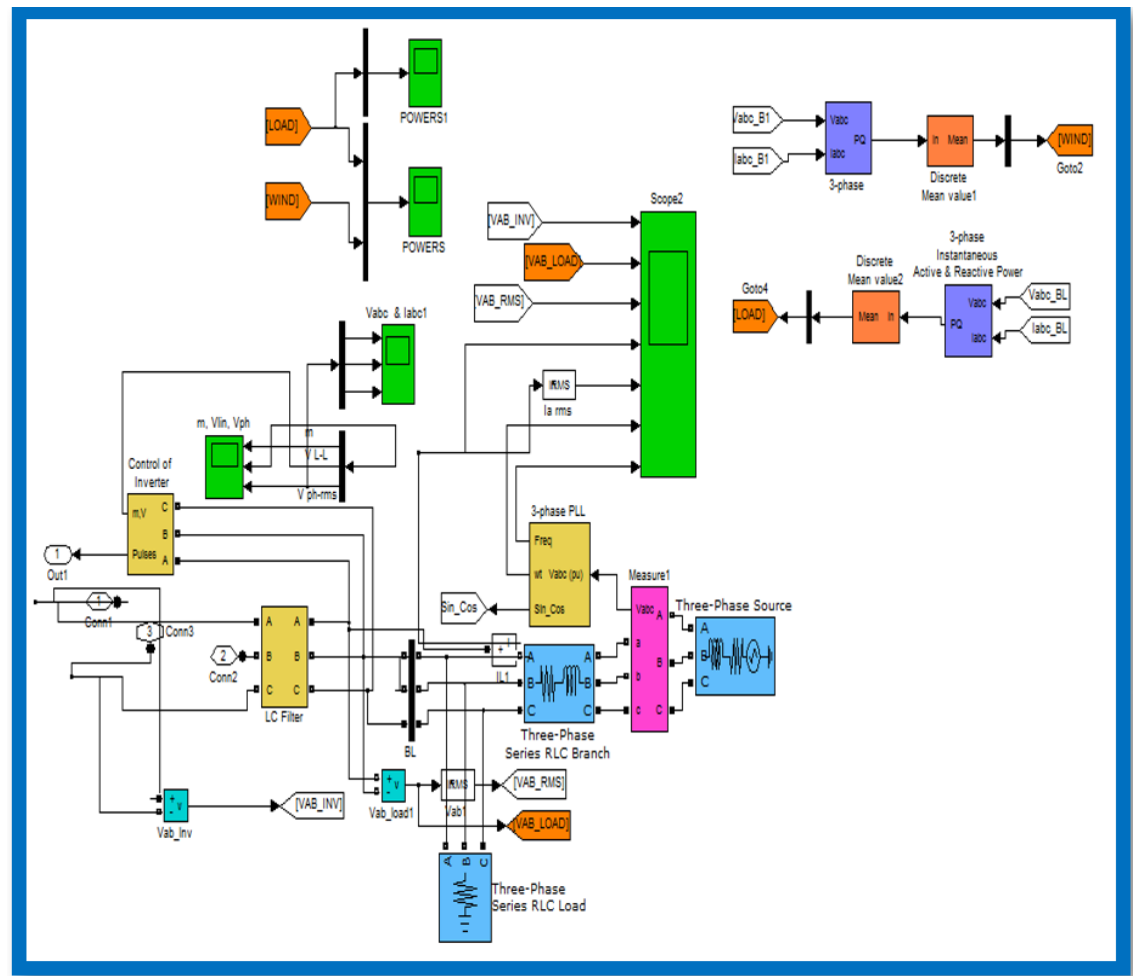

Figure 10 Waveform of AC grid connected load, (a) voltage at inverter (b) voltage at load (c) RMS voltage at inverter (d) RMS current of load at terminal ab (e) RMS current of load at terminal ab (f) rotor speed (g) frequency (see online version for colours)

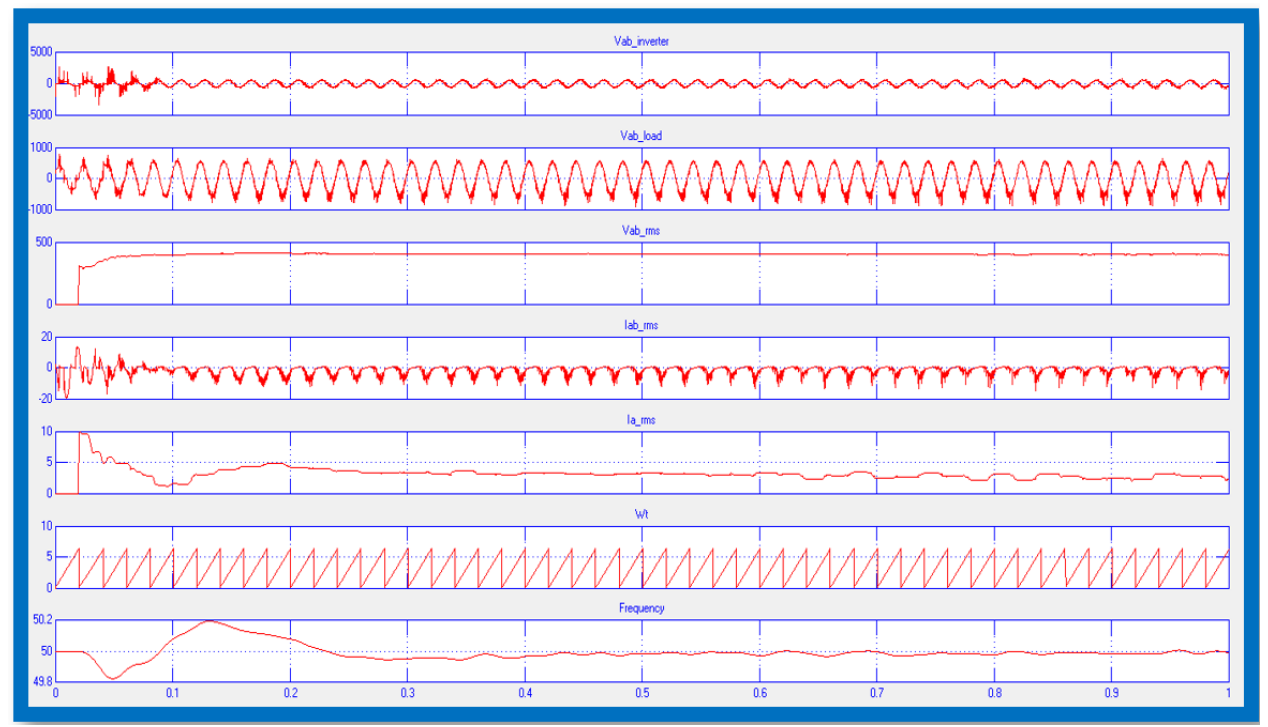




\section{References}

Agarwal, A. and Agarwal, V. (2012) 'FPGA Based variable frequency AC to AC power conversion', Electric Power Systems Research, Vol. 90, pp.67-78, DOI: 10.1109/ECCE.2013.6647419.

Agarwal, P., Sonkar, P. and Agarwal, V. (2012) 'Single phase to three phase cycloinverter with space vector PWM controller', 2012 IEEE Conference on Power Electronics, Derive and Energy System, Bengaluru, India.

Pouresmaeil, E., Montesinos-Miracle, D. et al. (2012) 'Control scheme of three-level NPC inverter for integration of renewable energy resources into AC grid', IEEE, June, Vol. 6, No. 2, pp.242-253.

Uehara, A., Pratap, A. et al (2011) 'A coordinated control methods to smooth wind power fluctuations of a PMSG based WECS', IEEE Transaction on Energy Conversion, June, Vol. 6, No. 2, pp.550-558.

Ullah, N.R., Thiringer, T. and Karlsson, D. (2007) 'Voltage and transient stability support by wind farm complying with the E.ON Netz grid code', IEEE Transaction on power Systems, Vol. 22, No. 4, pp.1647-1656.

Varma (2011) 'Grid interconnection of renewable source at the distribution level with power quality improvement features', IEEE.

Xu, L., Zhi, D. et al. (2007) 'Direct power control of grid connected voltage source converters', IEEE Power Engineering Society General Meeting, pp.1-6.

Yamazaki, K., Satoshi, K., Fukushima, N., Yamada, S. and Tada, S. (2012) 'Characteristics analysis of large high speed induction motors using 3-D finite element method', IEEE Transactions on Magnetics, Vol. 48, No. 2, pp.995-998. 